\title{
A Study on the Disaster Field Response Procedure and Triage Using Disaster Tabletop
}

\author{
Hyun-Mo Yang ${ }^{1}$, Gyoung-Yong Kim² \\ ${ }^{1}$ Professor, Department of Paramedic Science, Korea National University of Transportation, Korea, \\ emtyang@naver.com \\ ${ }^{2}$ Professor, Department of Paramedic Science, Korea National University of Transportation, Korea, \\ sikpan26@naver.com
}

Corresponding author: Gyoung-Yong Kim

\begin{abstract}
In a disaster situation, paramedics are an important human resource for the primary response. However, most of the disaster education for paramedic students only provides theoretical lectures. The purpose of this study is to propose a disaster-related education method by applying a disaster scenario-based simulation program for paramedic students who will act as human resources in disasters. After conducting a pre-training survey, the equipment, record sheets, and communication systems used for disaster level training were explained. Then, regional manpower and space allocation, simulated disaster simulation, debriefing, and post-training survey and evaluation were conducted. Continuous variables were expressed as median and minimum and maximum values, repeated measured variables were analyzed using Wilcoxon's test, and nominal variables were expressed as frequencies and percentages. To compare the results before and after training, a corresponding sample t-test was performed, a Cronbach alpha value was calculated to evaluate the reliability of the questionnaire, and a Pearson correlation test was performed to determine the association between the questions. In the preliminary survey, the need for disaster education was 7.6 (5-10), and the job confidence as paramedics was 6.1 (2-10) when a disaster occurred. In addition, the confidence related to the severity classification in the event of a disaster was 6.2 (2-10), and the confidence in the system delivered to other medical staff was 5.0 (1-8). The responses to the questionnaire after the simulation showed that satisfaction with road training education was 9.0 (6-10), while road training was 8.6 (5-10) with regard to improving work understanding and confidence when a disaster occurred. In addition, the need for road map training was 9.0 (6-10), and the willingness to recommend education to people around you for disaster road training was 7.9 (4-10). In the event of a disaster before and after simulation training, the confidence in work as paramedics improved from 6.1(2-10) to 9.0(6-10) ( $\mathrm{p}<.001)$, and the confidence related to severity classification in the event of a disaster improved from 6.2(2-10) to 7.9( 4-10) ( $\mathrm{p}<.001)$. In addition, confidence in the delivery system to other medical staff improved from $5.0(1-8)$ to $8.1(4-10)(\mathrm{p}<.001)$, and the evaluation results asking for disaster-related knowledge were from 4.7 (1-7) to 5.1 ( 2-8), but it was not statistically significant $(\mathrm{p}=.050)$. In this regard, if instructors who can provide practical lectures are dispatched in the form of special lectures or help through workshops, it is thought that it will be easier to conduct disaster response training for each university.
\end{abstract}

Keywords: Disaster, Scenario-based Simulation, Paramedic Student, Disaster Tabletop, Disaster Education

Received: April 25, 2021; $1^{\text {st }}$ Review Result: June 8, 2021; $2^{\text {nd }}$ Review Result: July 27, 2021

Accepted: August 30, 2021 


\section{Introduction}

\subsection{Necessity of the Study}

Disaster refers to the occurrence of unintentional damage to a community when it exceeds its ability to respond appropriately and provide its medical resources[1]. As society changes rapidly, the current disasters become increasingly complex and diverse. In addition, in recent years, natural disasters and man-made disasters are mixed[2]. Therefore, education and training on disasters are essential for emergency medical workers, but simple lecture-style education is the most basic method of disaster education currently being conducted. In addition, disaster training, excluding lectures, is a comprehensive training conducted once or twice a year only. In the case of comprehensive training, high cost, a lot of manpower, and long preparation time are required. Due to various circumstances, it is practically impossible for all emergency medical personnel in the jurisdiction to participate. Therefore, it is questionable whether effective response will be possible when a disaster situation occurs. To this end, Korea established the Ministry of Public Safety and Security(MPSS) in 2014 to revise the law on emergency medical care and produce emergency response manuals for the state and local governments. Emergency medical workers are required to receive more than 12 hours of disaster medical education every year. However, there is still insufficient education and training for disaster medical care[3].

Paramedics consult, rescue, and transport emergency patients. They are also emergency medical workers engaged in first aid services during the field, transport, and when in a medical institution. It is a key job that responds first to disasters[4]. Paramedics must be able to respond appropriately to disasters. In addition, through the results of the program, a method of education on the management of emergency rescue and disaster-related courses will be proposed. The role of the Disaster Medical Assistance Team (DMAT) that directly treats patients at the disaster site, the identification and request of medical resources for the site, the mediation of interests, and communication with the public are the roles of public health. Paramedics are human resources capable of working in both DMAT and public health, and in this area, the understanding of disasters of paramedic students is practically very important. However, the most basic disaster education method of the Department of Paramedicine is lecture-type education, and practical education for disasters is insufficient[5]. In the study results, which surveyed hospital medical staff and staff who experienced a disaster, it was suggested that goaloriented strategies and practical education are essential for disaster education. In addition, most of the previous studies on the ability to perform tasks and perceptions related to disasters only focused on public officials or medical personnel who did not respond directly to the disaster scene. So, there is no research centered on students in the Department of Emergency Rescue. Therefore, it is time for a new educational method for paramedic students as well as lecture-centered education on the current disaster.

There are several difficulties in developing a curriculum that can strengthen the disaster response core competency of emergency medical personnel who will play the most important role in disaster medical response. Even if you try to expand and reorganize the current curriculum more effectively, there are time and space constraints. In addition to disaster medicine, emergency medical personnel must also complete various training courses such as basic resuscitation, specialized resuscitation, and specialized trauma treatment. Although the development of the curriculum requires financial support along with the participation of related professionals, the government's support tends to focus on the areas needed by government agencies rather than the overall field of disaster medicine education. In order to overcome these obstacles, it is necessary to develop a core competency-based curriculum that can fundamentally improve the ability to cope with disasters from a general curriculum that conveys knowledge about what trainees need to know. In addition, since the environment in a disaster situation is quite chaotic and works in a complex way, an education and training course that strengthens the 
skills competency to be applied in any disaster environment is needed rather than an independent skill education. In addition, in a disaster situation, government agencies such as firefighting and police, and in some cases, military and private volunteer organizations are involved in the response. An effective disaster response can be made within the command system. In addition, the education and training course based on the core competencies required for disaster response must consistently prepare the knowledge and skill response manuals that are distributed according to the type of disaster and the primary response organization. It must be provided in such a way that it can overcome the limitations of time and space of the training participants.

This study conducted a scenario-based simulation program for paramedic students who will act as human resources in response to a disaster. In addition, through the results of the program, the researchers would like to propose a method of education on the management of emergency rescue and disaster-related courses.

\subsection{Research Hypothesis}

Hypothesis 1: Simulation education using the disaster tabletop will have high knowledge and performance ability.

Hypothesis 2: Simulation education using the disaster tabletop will have high educational satisfaction.

\section{Materials and Methods}

\subsection{Research Participants}

[Table 1] General Characteristics of Participants

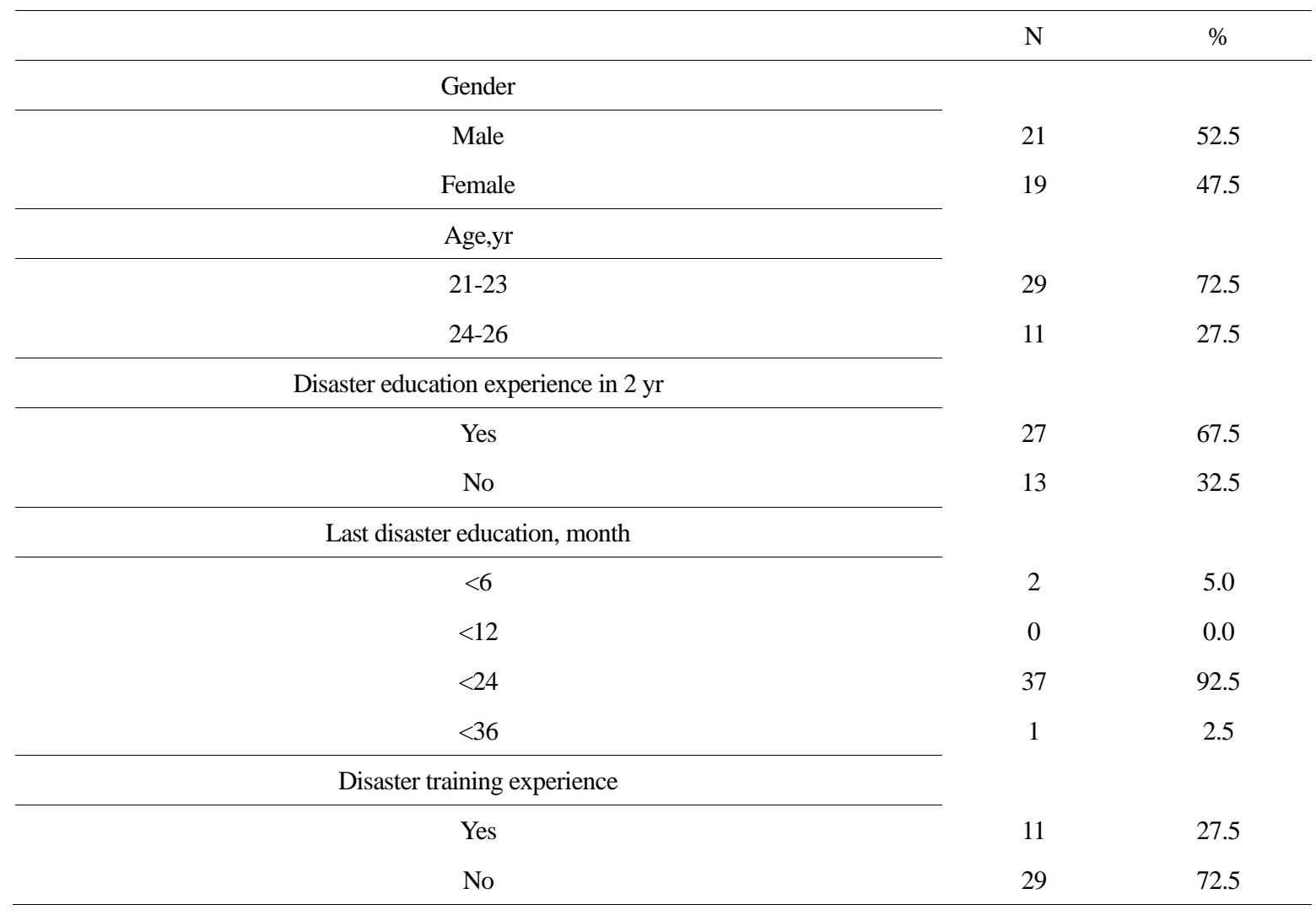


The participants of this study were students from the Department of Emergency Rescue at a certain university. They were from the same grade level and have completed all major courses relevant to disasters. Consent to the study was obtained along with a questionnaire asking the subjects about their health status. As a result, students who were unable to participate in the study due to health reasons and who did not wish to participate were excluded from the study. In addition, the subjects were informed that the can always stop participating if they wish to.

A total of 40 students participated in the study, twenty-one males $(52.5 \%)$, nineteen females (47.5\%), and the ages were twenty-one to twenty-three years old, twenty-nine (72.5\%), and twentyfour to twenty-six years old, eleven (27.5\%). Among the subjects of the study, twenty-seven (67.5\%) had experience in disaster education for the last two years, two $(5.0 \%)$ had education within six months to a year, and thirty-seven $(92.5 \%)$ were educated within one to two years, One $(2.5 \%)$ was within three years and eleven (27.5\%) had experience in disaster training [Table 1].

\subsection{Research Procedure}

\subsubsection{Research Instruments}

Among the preliminary questionnaires, the general characteristics included gender, age, whether there was a disaster education experience within 2 years, the last disaster education period, and the disaster training participation experience. In addition, the question was asked about the need for disaster education, confidence in work in the event of a disaster, patient treatment according to severity classification, and understanding of the system for delivering information to other medical staff and related persons. In addition, 10 questions were answered to find out the degree of understanding related to disasters.

\subsubsection{Research Design}

As for the disaster education program, the education program developed by the Catholic University Department of Emergency Medicine was modified and used by referring to the 2016 Emergency Medical Emergency Response Manual and the Educational Program Development Report of the Emergency Medicine Research Foundation. In order to develop an education program suitable for paramedics, one paramedic plans and trains hospital disaster drills every year, one paramedic is in charge of disaster lectures at the fire school, and the Department of Paramedicine is in charge of disaster education for students at the university. This wasbased on the recommendations of one professor.

\subsubsection{Data Collection Procedure}

After conducting a pre-training survey, the equipment, record sheets, and communication systems used for disaster level training were explained. Then, regional manpower and space allocation, simulated disaster simulation, debriefing, post-training survey and evaluation were conducted [Fig. 1].

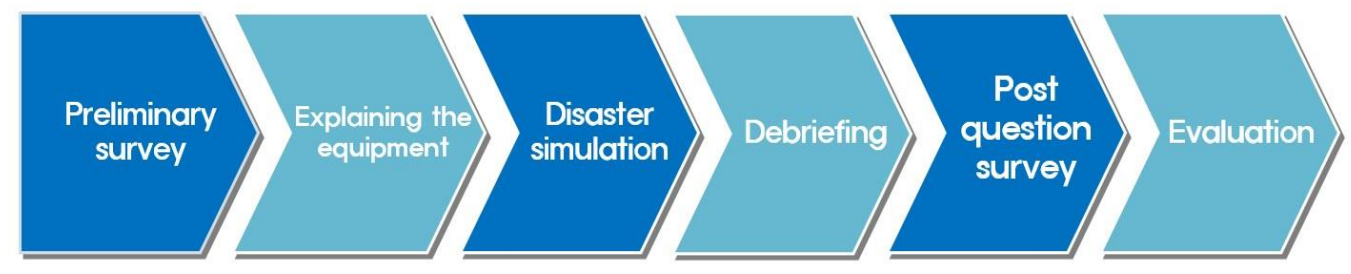

[Fig. 1] The Program Proceeds 
The scenario used for education was divided into two parts for multiple deaths due to an explosion accident at a nearby airport. The simulation lasted about 50 minutes. A large lecture hall at the university was used as the location of the educational program, and the number of participants was limited to 3 lecturers and 20 participants of the educational program in consideration of practical aspects. The video and sound effects of the disaster movie were used so that participants could immerse themselves in the actual situation. Before starting the education program, the curriculum manager explained the drawings used in the education program and the simulation process.

After completion, debriefing was conducted to share feelings and experiences with each other during the training process for each role. In the post questionnaire, the satisfaction with the simulation education, and the degree of need for the simulation education were asked period to They re-answer the 10 questions for understanding the disaster [Fig. 2].

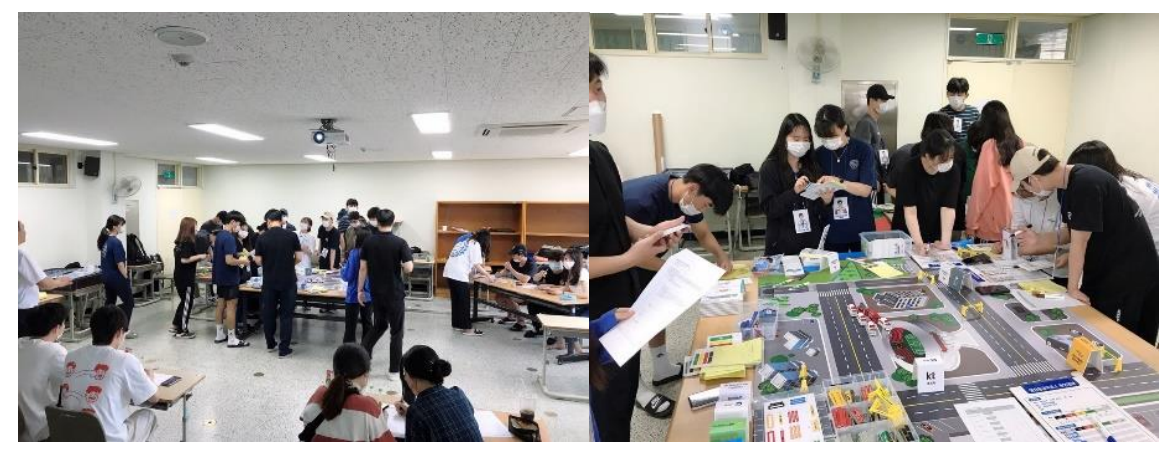

[Fig. 2] Simulation Settings and Drill

\subsubsection{Data Analysis}

For statistics, Window SPSS Statistics ver 21.0 (IBM Corp., Armonk, NY, USA) was used. Continuous variables were expressed as median and minimum and maximum values, repeated measured variables were analyzed using Wilcoxon's test, and nominal variables were expressed as frequencies and percentages. To compare the results before and after training, a corresponding sample t-test was performed, a Cronbach alpha value was calculated to evaluate the reliability of the questionnaire, and a Pearson correlation test was performed to determine the association between the questions.

\section{Results}

\subsection{Survey Results Before and After Simulation}

In the preliminary survey, the need for disaster education was $7.6(5-10)$, and the job confidence as paramedics was 6.1 (2-10) when a disaster occurred. In addition, the confidence related to the severity classification in the event of a disaster was $6.2(2-10)$, and the confidence in the system delivered to other medical staff was 5.0 (1-8).

The questionnaire after the simulation showed that satisfaction with road training education was 9.0 (6-10), while road training was 8.6 (5-10) with regard to improving work understanding and confidence when a disaster occurred. In addition, the need for road map training was 9.0 (6-10), and the willingness to recommend education to people around you for disaster road training was 7.9 (4-10) [Table 2]. 
[Table 2] Survey Results Before and After Simulation

\begin{tabular}{|c|c|c|}
\hline & Median & Min-Max \\
\hline \multicolumn{3}{|l|}{ Prequestionnaire } \\
\hline The need for disaster education & 7.6 & $(5-10)$ \\
\hline Confidence in the job of paramedic in case of a disaster & 6.1 & $(2-10)$ \\
\hline Confidence in performing patient treatment according to triage in case of disaster & 6.2 & $(2-10)$ \\
\hline Confidence in the delivery system to other medical staff related to the disaster & 5.0 & $(1-8)$ \\
\hline \multicolumn{3}{|l|}{ Questionnaire after simulation } \\
\hline Satisfaction with the disaster simulation education & 9.0 & $(6-10)$ \\
\hline $\begin{array}{l}\text { Simulation education improves work understanding and confidence in the event of a real } \\
\text { disaster }\end{array}$ & 8.6 & $(5-10)$ \\
\hline The need for table top simulation education & 9.0 & $(6-10)$ \\
\hline Confidence in efficient sharing of work with colleagues & 7.9 & $(4-10)$ \\
\hline
\end{tabular}

\subsection{Comparison of Results Before and After Simulation}

In the event of a disaster before and after simulation training, the confidence in work as paramedics improved from 6.1(2-10) to 9.0(6-10) $(\mathrm{p}<.001)$, and the confidence related to severity classification in the event of a disaster improved from 6.2(2-10) to 7.9( 4-10) $(\mathrm{p}<.001)$. In addition, confidence in the delivery system to other medical staff improved from 5.0 (1-8) to 8.1 (4-10) ( $\mathrm{p}<.001)$, and the evaluation results asking for disaster-related knowledge were from 4.7 (1-7) to 5.1 (2-8), but it was not statistically significant ( $\mathrm{p}=.050)$ [Table 3] [Fig. 3].

[Table 3] Comparison of Results Before and After Simulation Dducation

\begin{tabular}{|c|c|c|c|}
\hline & \multicolumn{2}{|c|}{ Median(Min-Max) } & \multirow{2}{*}{ p-value } \\
\hline & Pre-education & Post-education & \\
\hline Confidence in the job of paramedic in case of a disaster & $6.1(2-10)$ & $9.0(6-10)$ & $<.001$ \\
\hline $\begin{array}{l}\text { Confidence in performing patient treatment according to triage in } \\
\text { case of disaster }\end{array}$ & $6.2(2-10)$ & $7.9(4-10)$ & $<.001$ \\
\hline $\begin{array}{l}\text { Confidence in the delivery system to other medical staff related to } \\
\text { the disaster }\end{array}$ & $5.0(1-8)$ & $8.1(4-10)$ & $<.001$ \\
\hline Exam & $4.7(1-7)$ & $5.1(2-8)$ & .050 \\
\hline
\end{tabular}

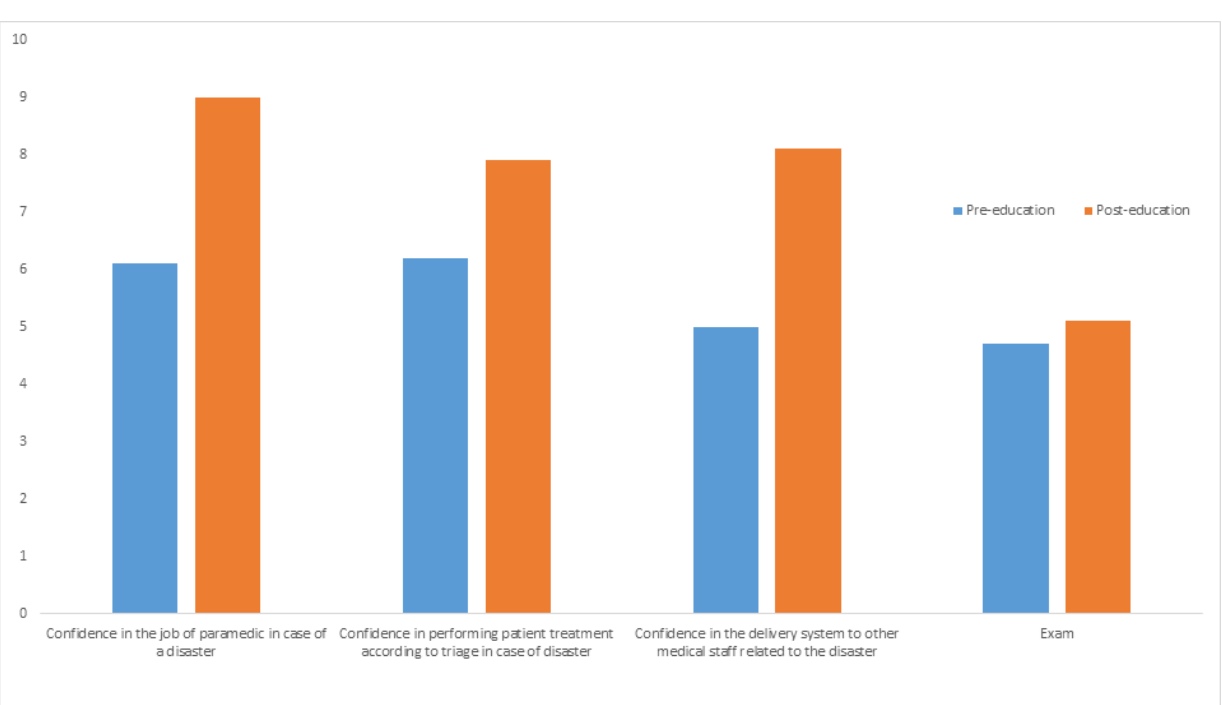

[Fig. 3] Comparison of Theoretical Test Evaluation Before and After Dducation 


\section{Discussion}

In general, disaster-related training is comprehensively carried out through several rehearsal exercises by planning annual training at hospitals or fire departments in the area, preparing scenarios that consider local characteristics. Through such disaster training, most of the disaster-related practice and experiences of paramedic students are in charge of the simulated patients and some necessary tasks in the disaster training. Of course, there is a positive effect of being able to experience the actual situation indirectly. But there is a limit to understanding the overall disaster response as well as understanding the degree of the role played by oneself. In order to effectively respond to disasters, all factors related to disasters must be organically progressed and managed in an integrated manner. Therefore, the disaster education method of paramedic students, who should be active as practical personnel for disaster emergency medical care in the future, should be more practical. In previous studies, it was shown that general education and training performed to develop individual disaster emergency medical competency did not affect the perception of emergency medical care management. In addition, since the number, method, and content of education and training for disaster safety management do not affect the individual's professionalism and competence, the existing education needs to be improved.

The American Medical Association has developed its own national disaster medical treatment process to strengthen response capabilities in the public health area in the event of a disaster[6]. Therefore, the national standard of disaster medical care is provided so that emergency medical workers, including emergency medical personnel, can systematically respond to disasters[7]. The national disaster medical education curriculum in the United States consists of a Basic Disaster Life Support course, an Advanced Disaster Life Support course, and a Core Disaster Life Support course. In addition to natural disasters, education courses are operated so that emergency medical workers can respond smoothly to various types of disasters such as explosives and biochemical terrorism.

Australia operates the UK's Major Incident, Medical Management and Support (MIMMS) course as an education and training course in disaster medicine[8][9]. The curriculum consists of a total of nineonline courses, three lectures, one skill course, two tabletop simulations, and three workshop courses. These trainings are conducted through practical training in the field, and a separate training course is being conducted as the importance of the commanders is highlighted[10].

In Europe, disaster medicine courses consist of a master's program at the graduate school, $84 \%$ of which consist of lectures, and the need for hands-on education is emerging, and the disaster training curriculum research group is developing a standardized disaster curriculum[11][12].

Japan operates a DMAT consisting of four to five doctors, nurses, and administrative staff in a single hospital for rapid team formation and operation rather than large-scale and diverse personnel in teams[13]. This was rapidly supplemented after the 2011 Great East Japan Earthquake, and the importance of disaster information for command and control was particularly emphasized. For this, based on the emergency medical information system (EMIS) using the Internet, disaster information was shared and activities were commanded and controlled. In disaster-related practice, the reporting process using EMIS was reinforced[14]. In addition, the Japanese program has many natural disasters caused by earthquakes, so lectures and simulation exercises are also organized around the earthquake response process.

In Korea, the National Medical Center developed a disaster medical emergency response manual and a disaster medical education and training program. In 2015, the Korean Disaster Life Support process is being implemented for disaster-disaster medical staff at disaster base hospitals. The contents of the training include how to wear personal protective equipment, practice of decontamination method, virtual training for in-hospital response, communication in a disaster situation, information collection and reporting, virtual training for mass casualties, and comprehensive training for disaster 
field response by DMAT. However, most of them are still focused on disaster sites[15][16]. In addition, opportunities for active sharing of opinions and skill acquisition are provided through disaster response symposiums conducted in the private sector, disaster workshops at local hospitals, disaster medical skills workshops, and simulation training. As such, KDLS education and workshops held at local hospitals are composed of essential contents at the disaster site. So, if this education is extended to students in the Department of Paramedicine, it is thought that opportunities for quality disaster education can be provided without developing another program.

In this study using a disaster tabletop, the confidence in work as paramedics was improved from $6.1(2-10)$ to 9.0 (6-10) in the event of a disaster after education was completed compared to before education. In addition, confidence in the severity classification improved from 6.2 (2-10) to 7.9 (4-10) $(\mathrm{p}<.001)$, and confidence in the disaster medical system delivered to other medical staff also increased from 5.0 (1-8) to 8.1. (4-10) ( $\mathrm{p}<.001)$. As such, the simulation education program related to disasters is an educational method that enables users to experience indirect experiences in a safe environment by setting virtually difficult situations that are practically difficult to experience. Compared to comprehensive training, spatial utility and cost savings can also be expected. And since it can be implemented even in situations where clinical practice and ambulance training due to infectious diseases is not possible, it is good to apply it to emergency rescue and disaster curriculum. In addition, it has the advantage of letting the students being able to understand the overall disaster response system or reporting system, and enabling repetitive practice in a short time. If you change roles and progress repeatedly, it will be helpful to understand the roles of other occupations that were difficult to experience through comprehensive training. However, in order to conduct disaster training using a disaster tabletop, there must be a lecturer who can operate an education program and the corresponding equipment is also required. In this regard, if instructors who can provide practical lectures are dispatched in the form of special lectures or help through workshops, it is thought that it will be easier to conduct disaster response training for each university.

\section{Conclusions}

The simulation education program related to disasters is an educational method that enables users to have indirect experiences in a safe environment by setting virtually difficult situations that are practically difficult to encounter. Compared to comprehensive training, spatial utility and cost savings can also be expected. And since it can be implemented even in situations where clinical practice and ambulance training due to infectious diseases is not possible, it is good to apply it to emergency rescue and disaster curriculum. In addition, it has the advantage of making students being able to understand the overall disaster response system or reporting system, and enabling repetitive practice in a short time. If you change roles and progress repeatedly, it will be helpful to understand the roles of other occupations that were difficult to experience through comprehensive training. However, in order to conduct disaster training using a disaster tabletop, there must be a lecturer who can operate an education program and the corresponding equipment is also required. In this regard, if instructors who can provide practical lectures are dispatched in the form of special lectures or help through workshops, it is thought that it will be easier to conduct disaster response training for each university. According to the results of this study, it is thought that if the training using the disaster tabletop is combined with disaster education for students in the paramedics field, it is expected that the job competency related to disaster will be improved. The limitation of this study is that only students enrolled in the Department of Paramedicine at one university were studied. In addition, not spending enough time for preeducation in proceeding with complex disaster scenarios, causes the subjects to experience confusion. Furthermore, the participants who played the role in medical institutions did not take realistic considerations such as functional paralysis of the depletion of medical resources and manpower of the 
institution. Therefore, the medical institution cannot consider the plan for the disaster because it is fully focused and participated in the disaster scenarios that are in progress in the educational program. In the future, it will be necessary to conduct a study to evaluate the effectiveness by conducting education using disaster tabletops for students from various universities along with various scenarios.

\section{Acknowledgments}

This work was supported by Korea National University of Transportation in 2020.

\section{References}

[1] Y. E. Kim, S. R. Yeom, Y. J. Jeon, M. Y. Lee, H. J. Yang, K. S. Park, S. Y. Woo, S. J. Lim, Public Health Disaster Response Team's awareness on disaster medical management capacity, Journal of the Korean Society of Emergency Medicine, (2020), Vol.31, No.1, pp.88-98.

[2 ] H. G. Moon, S. H. Kim, S. H. Oh, K. N. Park, Y. M. Kim, C. S. Youn, Single Center Experiences to Landslides on Woo-myun Mountain: Preparedness, Response, and Lessons Learned, Journal of the Korean Society of Emergency Medicine, (2013), Vol.24, No.1, pp.7-13.

[3] Y. S. Kim, H. M. Kim, B. H. So, W. J. Jeong, K. M. Cha, M. H. Oh, C. W. Jung, Experience of the Simulation Based Hospital Disaster Preparation Training Program by the Polls of before and after Training Program, Journal of the Korean Society of Emergency Medicine, (2016), Vol.27, No.6, pp.618-632.

[4] https://glaw.scourt.go.kr/wsjo/lawod/sjo190.do?contId=3242245\#, Dec 29 (2020)

[5] E. S. Choi, S. G. Hong, H. R. Kwon, B. Y. Koh, K. Y. Lee, H. H. Jung, M. L. Lee, S. W. Yun, S. E. Park, K. J. Cho, Standardization of a curriculum for paramedic students in South Korea, Journal of the Korea Society of Emergency Medical Services, (2017), Vol.24, No.1, pp.17-37.

[6] P. L. Coule, R. B. Schwartz, The national disaster life support programs: a model for competency-based standardized and locally relevant training, Journal of Public Health Management and Practice, (2009), Vol.15, No.2, pp.25-30, DOI:10.1097/01.PHH.0000345982.34551.99

[7] https://www.ndlsf.org/all-courses, May 12 (2021)

[8] J. Sammut, D. Cato, T. Homer, Major Incident Medical Management and Support (MIMMS): a practical, multiple casualty, disaster-site training course for all Australian health care personnel, Emergency Medicine Journal, (2001), Vol.13, No.2, pp.174-180, DOI: 10.1046/j.1442-2026.2001.00206.x

[9] http://www.nationaltraumacentre.nt.gov.au/what-we-do/disaster-management, Jun 11 (2016)

[10] P. Aitken, P. A. Leggat, A. G. Robertson, H. Harley, R. Speare, M. G. Leclercq, Education and training of Australian disaster medical assistance team members: results of a national survey, Prehospital and Disaster Medicine, (2011), Vol.26, No.1, pp.41-48, DOI: 10.1017/s1049023x10000087

[11] P. L. Ingrassia, M. Foletti, A. Djalali, P. Scarone, L. Ragazzoni, F. D. Corte, K. Kaptan, O. Lupescu, C. Arculeo, G. v. Arnim, T. Friedl, M. Ashkenazi, D. Heselmann, B. Hreckovski, A. Khorram-Manesh, R. Komadina, K. Lechner, C. Patru, F. M. Burkle, P. Fisher, Education and training initiatives for crisis management in the European Union: a webbased analysis of available programs, Prehospital and Disaster Medicine, (2014), Vol.29, No.2, pp.115-126, DOI: $10.1017 / \mathrm{S} 1049023 \mathrm{X} 14000235$

[12] A. Khorram-Manesh, M. Ashkenazi, A. Djalali, P. L. Ingrassia, T. Friedl, G. v. Armin, O. Lupesco, K. Kaptan, C. Arculeo, B. Hreckovski, R. Komadina, P. Fisher, S. Voigt, J. James, E. Gursky, Education in disaster management and emergencies: defining a new European course, Disaster Medicine and Public Health Preparedness, (2015), Vol.9, No.3, pp.245-255, DOI: $10.1017 / \mathrm{dmp} .2015 .9$

[13] A. Fuse, H. Yokota, An analysis of Japan Disaster Medical Assistance Team (J-DMAT) deployments in comparison with those of J-DMAT's counterpart in the United States (US-DMAT), Journal of Nippon Medical School, (2010), 
Vol.77, No.6, pp.318-324, DOI:10.1272/jnms.77.318

[14] H. Anan, O. Akasaka, H. Kondo, S. Nakayama, K. Morino, M. Homma, Y. Koido, Y. Otomo, Experience from the Great East Japan Earthquake response as the basis for revising the Japanese Disaster Medical Assistance Team (DMAT) training program, Disaster Medicine and Public Health Preparedness, (2014), Vol.8, No.6, pp.477-484, DOI: $10.1017 / \mathrm{dmp} .2014 .113$

[15] S. J. Wang, Emergency medicine in disasters, Hanyang Medical Reviews, (2015), Vol.35, No.1, pp.124-130.

[16] W. P. Hong, I. B. Kim, S. J. Wang, Experiences and lessons of the disaster medical assistance in Korea, Journal of the Korean Medical Association, (2014), Vol.57, No.12, pp.999-1007. 